\title{
4q21 microdeletion syndrome
}

INSERM

\section{Source}

INSERM. (1999). Orphanet: an online rare disease and orphan drug data base. 4921 microdeletion syndrome. ORPHA:238750

The 4q21 microdeletion syndrome is a newly described syndrome associated with facial dysmorphism, progressive growth restriction, severe intellectual deficit and absent or severely delayed speech. 